\title{
PROGRAMA DE MILHAS E CONTRATOS DE FIDELIDADE: NATUREZA JURÍDICA E IMPACTOS NO DIREITO DO CONSUMIDOR
}

\author{
FREQUENT FLYER (MILES) PROGRAM AND LOYALTY CONTRACTS: LEGAL \\ STATUS AND IMPACTS ON CONSUMER LAW
}

\section{RESUMO}

${ }^{1}$ Leonardo Raphael Carvalho de Matos

Tema relevante dentro das novas relações de consumo é a natureza jurídica dos programas de milhagem e contratos de fidelidade. A partir de uma visão pós-positivista, entende-se que os direitos do consumidor sofrem impacto direto do fenômeno da publicização do privado, ou seja, um reflexo constitucional nos interesses entre particulares, por constituírem parte integrante de um todo social, possuidores de direitos metaindividuais. Um dos aspectos a serem tratados é o que concerne à própria mutação legislativa no tocante à sua interpretação, no momento em que a norma jurídica se torna um composto de determinações normativas de caráter heterônomo e polissêmico, assumindo, então, uma nova natureza jurídica a partir de uma hermenêutica sistemática moderna. Ver-se-á, ainda, a influência dos princípios constitucionais no direito do consumidor como ciência jurídica, não apenas num plano ideológico (teórico), mas sob um aspecto prático, ao analisarem-se alguns casos em que pese um olhar público sobre os direitos dos consumidores e a defesa dos seus interesses nas decisões proferidas por magistrados, bem como pelos tribunais superiores brasileiros. Analisaremos a eventual natureza jurídica das milhas, por tratarem de uma nova forma de contratação de serviço, através de uma remuneração indireta, podendo ser encarada como moeda. O método de pesquisa será o hipotético-dedutivo.

Palavras-chave: Natureza jurídica, Programa de milhagens, Contrato de fidelidade

\begin{abstract}
Relevant theme within the new consumer relations is the legal nature of frequent flyer (miles) programs and loyalty contracts. From a post-positivist view, it is understood that the consumer's rights suffer direct impact of private publicity phenomenon, it means, a constitutional reflection in the interests of individuals, because they constitute an integral part of a social whole, metaindividual rights holders. One aspect to be addressed is what concerns the own legislative mutation with respect to its interpretation, at the time the legal norm becomes a compound of normative determinations of heteronomous and ambiguous character, assuming, then, a new legal from a modern systematic hermeneutics. Will be seen, also, the influence of constitutional principles on consumer rights as legal science, not just an ideological (theoretical) level, but from a practical aspect, when analyzing some cases, in spite of a public view on consumer rights and the defense of their interests in decisions handed down by judges as well as by Brazilian higher courts. We will review any legal nature of miles for addressing a new form of service contracts, through an indirect compensation, can be faced as a kind of money. The research method is the hypotheticaldeductive.
\end{abstract}

Keywords: Legal nature, Frequent flyer (miles) program, Loyalty contract

\footnotetext{
${ }^{1}$ Mestre em Justiça, Empresa e Sustentabilidade pela Universidade Nove de Julho - UNINOVE, São Paulo (Brasil) Professor pela Universidade Nove de Julho - UNINOVE, São Paulo (Brasil).

E-mail: leonardomatos.adv@ hotmail.com
} 


\section{INTRODUÇÃO}

A discussão sobre a natureza jurídica dos contratos de fidelidade e milhas ofertados pelas companhias aéreas esbarra em uma nova visão trazida pelo Código de Defesa do Consumidor (CDC) como evolução necessária do direito comum, cujo trabalho pioneiro pertence à Professora Claudia Lima Marques, um dos referenciais teóricos na presente pesquisa. Entende-se que não existem passagens aéreas grátis, quando oriundas de pontos alcançados em planos de milhas ou de fidelidade pela simples comparação entre os preços das empresas que não possuem esse tipo de serviço.

Houve um tempo em que as milhas eram prêmios recebidos a partir de viagens realizadas. Hoje, as milhas constituem moeda para a aquisição de produtos e/ou serviços diversos aos de viagens. As milhas, ainda, podem ser obtidas como produtos, através de simples compra. Da mesma forma que podem ser vendidas livremente. Logo, entende-se constituir moeda, sendo, esta, a sua natureza jurídica.

Como moeda, ela precisa de lei que a regule, e de previsão nos contratos de consumo. Faz-se necessário a sua inclusão nos estudos de mercado, nos tratados internacionais, no Direito Econômico e, claro, especialmente, no Direito do Consumidor. E este mesmo Direito precisa tutelar essas novas relações jurídicas, para que o consumidor não tenha seu direito violado por estas relações comerciais, inclusive quando estipuladas por contrato. Em se havendo contrato, não prosperam cláusulas abusivas (ou leoninas), que representam prejuízo aos consumidores.

Os programas de fidelidade estão na mira de alguns consumidores. Um dos questionamentos é se esses programas geram direitos transmissíveis aos herdeiros, em caso de morte do titular. Ou seja, sendo as milhas uma espécie de moeda, ou mesmo "prêmio", se este poderia ser transmitido a terceiros.

A maioria dos programas de fidelidade termina a partir do momento que o consumidor deixa de ser cliente pela sua morte, ou por vontade própria. As empresas entendem que este posicionamento não é abusivo ou ilegal, porque são benefícios e vantagens oferecidos a título de recompensa da fidelidade e também pela confiança mútua existente entre as partes. Contudo, ao se analisar pela perspectiva do consumidor, a impossibilidade de transmissibilidade “causa mortis” geraria um prejuízo à família do de cujus, principalmente, se preponderante a natureza de moeda.

Até pouco tempo atrás era possível pagar as compras do supermercado e abastecer o carro no posto de gasolina usando só reais ou, no máximo, vales refeição e combustível. 
Hoje, no entanto, o consumidor que gasta nesses estabelecimentos ganha pontos que acabam funcionando, na prática, como moedas paralelas na compra de produtos e serviços em outros estabelecimentos comerciais.

Essa grande malha de empresas entrelaçadas pelos pontos ganhos em compras, que podem ser usados como moedas de troca em outras lojas para adquirir produtos ou serviços, cresce a cada dia e virou um grande filão de negócio. Companhias especializadas em tornar o cliente fiel à loja ou à prestadora de serviço se autodenominam empresas de marketing e frisam que não estão ligadas ao setor financeiro.

Portanto, com esta pesquisa, objetiva-se analisar as milhas aéreas como produtos e/ou serviços indiretamente remunerados, com natureza jurídica de moeda, constituindo-se, ainda, como crédito transmissível a terceiros, inclusive causa mortis. Como se trata de um instituto moderno, o ordenamento jurídico brasileiro deve se readequar a esses novos contratos e novos direitos. E com isso, observam-se os impactos para o Direito do Consumidor nessas novas relações jurídicas.

Para efeito da presente pesquisa, entende-se que a análise da tutela dos direitos do consumidor é uma modalidade de pesquisa social aplicada. Compreende-se que análise é a expressão de um julgamento de valor, o que induz a determinar o que é satisfatório ou não nos contratos apontados, considerando as variáveis contextuais onde se restam implementados.

Ressalte-se que o ato de avaliar não é neutro nem exterior às relações de poder. É um ato técnico, mas também político. Não é desinteressado, mas exige objetividade e independência, fundamentando-se em valores e no conhecimento da realidade bem como nos sujeitos envolvidos nos contratos de consumo.

Pretende-se nesta abordagem realizar uma análise crítica dos programas de milhagem e fidelização, com o escopo de identificar e avaliar os sujeitos, interesses e racionalidades presentes no processo de contratação desses produtos e serviços e suas intervenções na efetivação dos direitos do consumidor.

Primeiramente, far-se-á levantamento bibliográfico sobre a temática e um estudo orientado sobre a natureza jurídica dos programas de milhagem e dos contratos de fidelidade, e sua aplicabilidade ao contexto atual de exploração contratual e vulnerabilidades do consumidor.

Utilizando-se método hipotético-dedutivo de pesquisa social para este projeto, procurar-se-á o estabelecimento de relações, a fim de confrontar os propósitos dos programas 
e os impactos qualitativos gerados na vida do consumidor contratante, a partir da análise da literatura pertinente ao tema e dos julgados das cortes superiores brasileiras.

\section{MILHAS AÉREAS E CONTRATO DE FIDELIDADE: NATUREZA JURÍDICA E IMPACTOS NAS RELAÇÕES DE CONSUMO}

Entende-se que o plano de milhagem para o consumidor funciona como se lhe fosse entregue um carnê cujas parcelas são pagas periodicamente, até atingir o valor final, em forma de bilhete aéreo. Os contratos de milhas ou fidelidade seguem os seguintes modelos. Portanto, caso venham cessar as atividades, uma empresa do setor não pode deixar de honrar seus compromissos apenas com fornecedores, bancos e impostos. A companhia que a suceder terá que arcar com a entrega de passagens, via milhas, já que os pontos são créditos cumulados nas mãos dos consumidores, que pertencem à categoria de credores de um serviço, e a companhia aérea passa a ser devedora da obrigação de fazer.

O direito adquirido se consolida a cada prestação paga, ou seja, a cada ponto (ou grupos de pontos) somado. Tendo alcançado o total de pontos em contrato, o consumidor poderá marcar a passagem para o destino desejado, nos horários disponíveis, sem discussão. A legítima expectativa do consumidor ao acreditar e devotar fidelidade àquela empresa deve ser atendida, pois, afinal, foram muitas viagens e despesas pagas, que geraram lucros em contrapartida.

Entende-se que o direito ao crédito não é mera liberalidade ou brinde, como se posiciona a Agência Nacional de Aviação Civil (ANAC), que regula o setor de aviação civil. Trata-se de um crédito especial, posto que representa exercício do direito subjetivo de viajar. Milhagem não é brinde: é ticket pago antecipadamente, de forma indireta, com direito a uso posterior. As companhias aéreas já embolsaram o pagamento de seu preço, embutido na venda de passagens regulares.

Tais créditos que, em princípio são de propriedade da companhia aérea, possuem vínculo obrigatório com o contrato principal, que obriga o consumidor (se quiser pontuar) em viajar somente através daquela companhia, em adquirir produtos ou serviços somente com os parceiros da mesma companhia ou com um cartão de crédito emitido por ela. Um exemplo disso é o passageiro que tenha consigo um bilhete de uma determinada companhia e apresente o cartão para pontuar por outra companhia, que sequer faça parte do mesmo grupo. Conseguirá ele pontuar suas milhas? A resposta está no site de uma companhia aérea: "Caso 
você participe de mais de um programa de milhagem de companhias aéreas parceiras do fidelidade, não haverá possibilidade de transferência de pontuação, transformando milhas em pontos ou vice-versa. Os programas são distintos e independentes, em outros acordos de codeshare e/ou franquia."

Como se observa existe uma legítima pretensão empresarial por traz disso, cujo marketing não se dá a título gratuito, mas por interesse em cativar clientes. Se a finalidade do consumidor é receber o bilhete e empreender a viagem, a do fornecedor é a de ser remunerado, de obter mais clientes fiéis ao seu produto ou serviço e de gerar lucros.

É o que Claudia Lima Marques denomina de "falácia da gratuidade", onde a expressão remunerado significa uma importante abertura para incluir os serviços de consumo remunerados indiretamente, isto é, quando não é o consumidor individual que paga, mas a coletividade, através da facilidade diluída no preço de todos. Ela inclui nesse rol todos os contratos em que for possível identificar a contraprestação escondida, em contratos considerados unilaterais, como o mútuo, cujo modelo é conhecido na poupança popular.

Nos Estados Unidos, analistas de mercado importantes alertam para a falácia econômica dos chamados serviços, utilidades ou promessas gratuitas, que não passaria de uma superada ficção jurídica. Se a relação de consumo tem como finalidade algum tipo de remuneração, mesmo que indireta do fornecedor está ela incluída no regime do Código de Defesa do Consumidor, como comprova até mesmo o artigo 39, inciso III e parágrafo único que visam regular relações gratuitas, mas claramente de consumo.

A falácia da gratuidade esconde a onerosidade nos preços das passagens, nos encargos dos cartões de crédito ou nas diárias de um hotel. Esses direitos serão tratados de forma coletiva, como natureza indivisível e que, portanto, estão ligados por uma relação jurídica base (contrato e dever legal) com as empresas aéreas, suas sucessoras e até mesmo com a agência governamental, que deve zelar pela concessão, fiscalizar com rigor e não se omitir quando uma concessionária é administrada de forma desastrosa.

$\mathrm{O}$ não-cumprimento das obrigações com os consumidores levará à execução específica de que trata o artigo 84 do Código de Defesa do Consumidor, cabendo ao Poder Judiciário a última decisão.

É importante ressaltar que os benefícios desses programas são de uso limitativo e a aplicação das regras deve ser analisada caso a caso. Os programas são livremente instituídos pelas empresas, mas as condições e limitações de uso devem ser informadas aos consumidores. Dessa forma, as empresas devem cumprir o contrato escrito, bem como as ofertas divulgadas por qualquer outro meio de publicidade. 
Em São Paulo, tramita uma Ação Civil Pública contra uma empresa aérea, ajuizada pela Proteste Associação de Defesa dos Direitos dos Consumidores em que se pretende:

a) que os bilhetes emitidos pela empresa aérea tenham validade de um ano, como determina a Lei $n^{\circ}$ 7.565/86 (Código Brasileiro de Aeronáutica);

b) que os pontos acumulados não se extingam com a morte do titular, mas respeitem as regras do direito de sucessão;

c) que todas as alterações de regulamento sejam informadas aos consumidores com 90 dias de antecedência;

d) e que os pontos acumulados não se extingam com o prazo de 24 meses (ou dois anos), mas tenham validade ilimitada.

Nesta ação, a Justiça paulista concedeu liminar para suspender os efeitos de cláusulas do regulamento do programa de fidelidade da empresa aérea que tratam especificamente (i) da validade do bilhete; (ii) da transmissibilidade dos pontos aos herdeiros; (iii) do direito à informação das alterações feitas nos regulamentos; e (iv) da prescrição dos pontos.

O Poder Judiciário determinou que o bilhete de passagem aérea deveria ter validade de um ano, a partir da data de sua emissão, que os pontos do titular devem ser transmitidos aos herdeiros, em caso de morte, e que as alterações de regulamento têm de ser informadas com 90 dias de antecedência. Além disso, determinou que os pontos acumulados de milhas não devem ser extintos no prazo de dois anos e valem por tempo indeterminado. A empresa aérea recorreu e essa decisão foi cassada pelo Tribunal de Justiça de São Paulo até decisão final sobre o recurso da companhia, que aguarda julgamento.

Em outro caso, o Tribunal de Justiça de Minas Gerais manteve o indeferimento de liminar em recurso interposto por uma empresa aérea, que queria impedir a venda de pontos por meio de um site. O fundamento da decisão foi o de que o contrato dos pontos é oneroso e, portanto, é insubsistente qualquer cláusula de inalienabilidade desse tipo de produto. A ação continua a tramitar, sem decisão definitiva sobre a questão.

O assunto é tão polêmico que há, ainda, Projeto de Lei tramitando na Câmara dos Deputados para regular a matéria. O Projeto de Lei $\mathrm{n}^{\circ}$ 4015, de 2012, de autoria do Deputado Carlos Bezerra (PMDB/MT), dispõe sobre a prescrição dos pontos acumulados em programas de fidelidade. A Comissão de Defesa do Consumidor aprovou, em reunião deliberativa extraordinária em dezembro de 2014, um substitutivo ao projeto apresentado. O substitutivo dispõe não só sobre a prescrição, mas sobre as demais regras aplicáveis aos programas de 
fidelidade. Ele “dispõe sobre o tratamento dado aos pontos creditados em nome do consumidor por programas de fidelidade ou redes de programa de fidelidade, instituídos por fornecedores”. Atualmente, o projeto está com a Comissão de Constituição e Justiça e de Cidadania (CCJC) para aprovação.

Um ponto interessante do substitutivo ao projeto de lei é a proposta de que, caso as empresas descumpram as regras, podem ser penalizadas com $20 \%$ em pontos e não em moeda corrente. Assim, é possível entender que os pontos oriundos de programas de fidelidade não podem ser equiparados à moeda corrente e por ela serem substituídos, caso as empresas não queiram. Isso deveria ficar mais claro no projeto. Também, seria recomendável inserir um dispositivo sobre a observância dos regulamentos das empresas para as demais regras não dispostas no PL, ou que em tais regulamentos conste expresso dispositivo sobre a transmissibilidade ou não dos pontos aos herdeiros, em caso de morte do titular.

O relator do projeto de lei sustentou que não é razoável que o Estado imponha regras demasiadas às empresas. Obviamente que isso ofenderia o princípio da livre iniciativa e ensejaria um efeito reverso prejudicando o próprio consumidor. A vontade do legislador não é criar regras rígidas aos programas de fidelidade, pois acredita que esse não é o caminho para a melhoria e apoio à criação de novos benefícios, inclusive em outros segmentos. Como são programas de fidelidade instituídos livremente para atrair consumidores, as empresas podem encerrá-los.

As vantagens oferecidas não possuem "natureza econômica". Caso contrário, teriam que ser declaradas em Imposto de Renda, consignadas em inventários, etc. É importante ressaltar que esses programas têm benefícios limitativos, personalíssimos e intransferíveis. As partes devem, portanto, respeitar todas as regras dispostas nos regulamentos.

Outro ponto importante a se discutir é o ingresso dos programas de fidelização no mercado varejista. Sob o mote de conseguir ampliar em até $10 \%$ a receita dos varejistas no prazo de 12 meses, as metas dessas empresas de fidelização traçadas para este ano são ambiciosas. A Dotz, por exemplo, que batizou os pontos com o mesmo nome da empresa e chama esses pontos de "a segunda moeda", quer dobrar de tamanho em 12 meses.

A empresa, que começou em 2000 atendendo lojas virtuais e estreou no varejo físico há quatro anos, fechou 2013 com 11,5 milhões de consumidores cadastrados e atuação em nove praças, entre as quais estão o interior de São Paulo, Belo Horizonte, Brasília, Paraná, Santa Catarina, por exemplo. Para este ano, Roberto Chade, presidente da empresa, diz que a meta é ter perto de 20 milhões de usuários de Dotz e estar presente em 14 ou 15 praças. 
Carlos Formigari, presidente da Netpoints, que recentemente teve uma participação de 25\% adquirida pela Smiles, observa que o negócio de fidelidade no Brasil está só engatinhando, quando comparado aos EUA e países da Europa. No exterior, observa, o consumidor já trabalha com esse conceito de obter vantagens em outros estabelecimentos quando adquire um determinado produto ou serviço.

A empresa, que começou em 2011 e tem 4 milhões de usuários e mais de 100 estabelecimentos físicos e online que usam o sistema de pontuação, tem planos ambiciosos para este ano. "Nosso objetivo é deixar de ser uma empresa regional, com atuação só no Estado de São Paulo, para ser uma companhia nacional”, prevê Formigari. Ele quer triplicar o número de consumidores em 12 meses.

A Multiplus, criada em meados de 2009 como uma unidade de negócios da TAM, tornou-se uma empresa independente no fim de 2009. A companhia informa que tem mais de 11 milhões de usuários no programa de pontos e que a sua participação no varejo varia entre $7 \%$ a $8 \%$. A meta em três anos é expandir essa participação para algo entre $20 \%$ a $25 \%$ no varejo de resgate de pontos.

Para o economista Francisco Petros, ex-presidente da APIMEC (Associação dos Analistas e Profissionais de Investimento do Mercado de Capitais), esses sistemas de pontuação que crescem exponencialmente no varejo envolvem riscos jurídicos. O primeiro risco, aponta Petros, diz respeito aos contratos. Podem existir possíveis cobranças judiciais futuras de créditos que o consumidor eventualmente tem direito ou pensa ter direito e que pode ser imposto às empresas.

$\mathrm{O}$ segundo risco se refere aos direitos à privacidade. Como o objetivo desses programas de pontos é conhecer o consumidor, obtendo dados sobre o seu perfil socioeconômico e o comportamento de compras, o economista acredita que isso pode envolver, no futuro, demandas jurídicas de consumidores que viram a vida financeira ser esmiuçada. Na maioria das vezes, esses consumidores, atraídos pelas vantagens que esses pontos (ou essas quase moedas) podem proporcionar, não avaliam a exposição a que estão submetidos.

Os estudos desenvolvidos a partir da teoria Pós-positivista do Direito tomam por base os Princípios Constitucionais e sua efetividade no Direito Privado, superando-se a dicotomia entre o público e o privado, a partir da hermenêutica sistemática das normas e sua polissemia.

Com o Direito do Consumidor também é assim. Este recebe influência direta dos Princípios Constitucionais e por uma interpretação sistêmica, constitui seus próprios 
princípios. Entre eles, destacam-se alguns que precisam ser observados nos contratos que possuem por objeto os programas de milhagem ou fidelidade.

Entre eles, destacam-se:

a) Princípio da Informação

A informação, ou melhor, o direito de informação, na Constituição Federal pode ser contemplado sob três aspectos: o direito de informar, o direito de se informar e o direito de ser informado.

O direito de informar é uma prerrogativa constitucional concedida às pessoas físicas e jurídicas. É o dispositivo do caput do artigo 220 que dispõe, in verbis:

\footnotetext{
A manifestação do pensamento, a criação, a expressão e a informação, sob qualquer forma, processo ou veículo não sofrerão qualquer restrição, observado o dispositivo nesta Constituição.
}

Essa norma é solidificada por outra pétrea das garantias fundamentais. A do inciso IX do artigo $5^{\circ}$, que dispõe, in verbis: "é livre a expressão da atividade intelectual, artística, científica e de comunicação, independentemente de censura ou licença”.

Trata-se de um dever exigido mesmo antes de se iniciar qualquer relação. Impõe- se ao fornecedor o dever de informar na fase pré-contratual, isto é, na oferta, na apresentação e na publicidade. E essa informação obrigatória vai integrar o contrato, como dispõe o artigo 30 do CDC:

Toda informação ou publicidade, suficientemente precisa, veiculada por qualquer forma ou meio de comunicação com relação a produtos e serviços oferecidos ou apresentados, obriga o fornecedor que a fizer veicular ou dela se utilizar e integra o contrato que vier a ser celebrado.

A ratio legis do CDC é justamente valorizar este momento de formação do contrato de consumo. A tendência atual é de examinar a qualidade da vontade manifestada pelo contratante mais fraco, mais do que a sua simples manifestação: somente a vontade racional, a vontade realmente livre (autônoma) e informada, legítima, isto é, tem o poder de ditar a formação e, por consequência, os efeitos dos contratos entre consumidor e fornecedor.

A tendência atual é de examinar também a conduta negocial do fornecedor, valorizando-a e controlando-a, dependendo da conduta (abusiva ou não) a formação do vínculo (informações prévias, acesso ao contrato, envio de mercadorias não requeridas etc.) e a interpretação de a quais obrigações o consumidor está vinculado (MARQUES, 2010, p. 649).

O direito de se informar é uma prerrogativa concedida às pessoas. Decorre do fato da existência da informação. O texto constitucional, no inciso XIV do artigo $5^{\circ}$, assegura 
primeiramente esse direito no que diz respeito à informação em geral, mas garante o sigilo da fonte, quando necessário ao exercício profissional.

Sabe-se que o exercício de um direito subjetivo significa a possibilidade da exigência de alguém. Isto é, a prerrogativa de um corresponde à obrigação de outro. Assim, quando a Constituição garante a todos o acesso à informação, tem-se de entender que essa informação deve estar com alguém que terá a obrigação de fornecê-la.

No âmbito constitucional o direito de ser informado é menos amplo do que no sistema infraconstitucional de defesa do consumidor. $\mathrm{O}$ direito de ser informado nasce, sempre, do dever que alguém tem de informar.

\begin{abstract}
Informar é comunicar, é compartilhar o que se sabe de boa-fé, é cooperar com o outro, é tornar "comum" o que era sabido apenas por um. Informar é dar forma, é exteriorizar o que estava interno, é compartilhar, é comunico-are, é chegar ao outro, é aproximarse. Informação é tema transversal e multifacetado do direito privado. Informação é, ao mesmo tempo, um estado subjetivo, é o saber ou o não saber; informação é um processo interativo, que se denomina normalmente de comunicação; informação é um conteúdo, são os dados, saberes, conhecimento, imagens, sons, formas, palavras, símbolos ou (in)formações organizadas e, acima de tudo, informação é um direito. (MARQUES, 2010, p. 651)
\end{abstract}

Além disso, como a informação está ligada ao princípio da moralidade, é de extrair daí o conteúdo ético necessário que deve pautar a informação fornecida. E ele é o valor ético fundamental da verdade.

O dever de informar é dever oriundo da boa-fé e altamente valorado na complexa
sociedade de riscos e da informação contemporânea. Como ensinam Ossola e
Vallespinos, o que existe atualmente nos contratos complexos contemporâneos é
uma "necessidade de informação". Como relembra o mestre Clóvis do Couto e
Silva, desde 1902, H. Staub ensinava que a boa-fé é uma fonte autônoma de deveres
de informação, de cooperação e de cuidado para com o outro, com o parceiro
contratual, e que a violação destes deveres secundários ou anexos é um dano, um
incumprimento por si só (quebra positiva do contrato). Daí podermos chamar de
dano "informativo", isto é, o dano derivado do incumprimento do dever autônomo e
de boa-fé de informar clara e adequadamente, tão importante e decisivo hoje nas
relações de consumo. (MARQUES, 2010, p. 651)

Desta forma assevera Luis Antonio Rizzatto Nunes:

A informação não pode faltar com a verdade daquilo que informa de maneira alguma, quer seja por afirmação, quer por omissão. Nem mesmo manipulando frases, sons e imagens para, de maneira confusa ou ambígua, iludir o destinatário da informação. (NUNES, 2011, p. 99)

Assim, tanto no artigo 37 (que regula a Publicidade) quanto no capítulo da comunicação social a Carta Magna protege a ética. E para fins de publicidade em matéria de relações de consumo, o valor ético fundamental é o da verdade.

b) Princípio da Transparência 
O princípio da transparência, expresso no caput do artigo $4^{\circ}$ do CDC, se traduz na obrigação do fornecedor dar ao consumidor a oportunidade de conhecer os produtos e serviços que são oferecidos e, também, gerará no contrato a obrigação de propiciar-lhe o conhecimento prévio do seu conteúdo e suas condições.

O princípio da transparência será contemplado pelo princípio do dever de informar, previsto no artigo $6^{\circ}$, inciso III, e a obrigação de apresentar previamente o conteúdo do contrato está regrada no artigo 46 do CDC.

Transparência significa informação clara e correta sobre o produto a ser vendido, sobre o contrato a ser firmado, significa lealdade e respeito nas relações entre fornecedor e consumidor, mesmo na fase pré-contratual, isto é, na fase negocial dos contratos de consumo.

O princípio da transparência rege o momento pré-contratual, rege a eventual conclusão do contrato. É mais do que um simples elemento formal, afeta a essência do negócio, pois a informação repassada ou requerida integra o conteúdo do contrato ou, se falha, representa a falha na qualidade do produto ou serviço oferecido. Tal princípio concretiza a ideia de reequilíbrio de forças nas relações de consumo, em especial, na conclusão de contratos de consumo, imposto pelo CDC como forma de alcançar a almejada justiça contratual. (MARQUES, 2010, p. 650)

c) Princípio da Vulnerabilidade

O artigo $4^{\circ}$, inciso I reconhece o consumidor como vulnerável. Tal reconhecimento é uma medida de realização da isonomia garantida na Constituição Federal. Significa que o consumidor é a parte fraca na relação jurídica de consumo. Essa fraqueza é real e decorre de dois aspectos: um de ordem técnica e outro de cunho econômico.

O primeiro está ligado aos meios de produção, cujo conhecimento é monopólio do fornecedor. E quando se fala em meios de produção não se está apenas referindo aos aspectos técnicos e administrativos para a fabricação e distribuição de produtos e prestação de serviços que o fornecedor detém, mas também ao elemento fundamental da decisão: é o fornecedor que escolhe o que, quando e como produzir, de sorte que o consumidor está à mercê daquilo que é produzido.

É por isso que, quando se fala em "escolha" do consumidor, ela já nasce reduzida. O consumidor só pode optar por aquilo que existe e foi oferecido no mercado. E essa oferta foi decidida unilateralmente pelo fornecedor, visando seus interesses empresariais, que são, por evidente, os da obtenção de lucro. (NUNES, 2011, p. 175)

O segundo aspecto, o econômico, diz respeito à maior capacidade econômica que, por via de regra, o fornecedor tem em relação ao consumidor. É fato que há consumidores individuais com boa capacidade econômica e às vezes, até superior à de pequenos fornecedores. Mas essa é a exceção da regra geral.

d) Princípio da Liberdade de escolha 
A liberdade de escolha garantida ao consumidor tem fundamento no princípio da liberdade de ação e escolha da Constituição Federal (artigo $1^{\circ}$, III; artigo $3^{\circ}$, I; artigo $5^{\circ}$, caput, entre outros). Tem, também, relação indireta com o princípio da vulnerabilidade previsto no artigo $4^{\circ}$, inciso I do CDC.

Logo, os contratos de fidelidade com as empresas aéreas precisam respeitar os princípios ora citados, sob pena de ferir os direitos básicos do consumidor e serem considerados contratos abusivos, com cláusula leoninas que auferem prejuízo e condições desproporcionais à vulnerabilidade presumida do consumidor.

Outro aspecto importante quanto à natureza jurídica das milhas aéreas é considerá-las como um serviço. Serviço é, tipicamente, atividade. Esta é a ação humana que tem em vista uma finalidade. Ora, toda ação se esgota tão logo praticada. A ação se exerce em si mesma. Daí somente poderia existir serviço não durável.

Seria uma espécie de contradição falar em serviço que dura. Todavia, o mercado acabou criando os chamados serviços duráveis, tais como os contínuos (por exemplo, os serviços dos planos de saúde, os serviços educacionais regulares e os serviços de fidelidade). Com isso, o Código de Defesa do Consumidor, incorporando essa invenção, trata de definir também os serviços como duráveis e não duráveis. A hipótese dessa divisão, da mesma forma que quanto aos produtos, está tratada no art. 26, I e II.

\footnotetext{
Serviços duráveis serão aqueles que: a) tiverem continuidade no tempo em decorrência de uma estipulação contratual (...); b) embora típicos de não durabilidade e sem estabelecimento contratual de continuidade, deixarem como resultado um produto (...). Nesses casos, embora se possa destacar o serviço do produto deixado (o que gerará diferenciais no aspecto da responsabilidade), o produto faz parte do serviço (...). (NUNES, 2011, p. 145 e 146)
}

O Código de Defesa do Consumidor define serviço como aquela atividade fornecida mediante remuneração, de acordo com o artigo $3^{\circ}$, parágrafo $2^{\circ}$, do CDC. Antes de mais nada, consigne-se que praticamente nada é gratuito no mercado de consumo, principalmente, as milhas aéreas. Tudo tem, na pior das hipóteses, um custo, e este acaba, direta ou indiretamente, sendo repassado ao consumidor.

\footnotetext{
Logo, quando a lei fala em "remuneração" não está necessariamente se referindo a preço ou preço cobrado. Deve-se entender o aspecto "remuneração" no sentido estrito de qualquer tipo de cobrança ou repasse, direto ou indireto. (NUNES, 2011, p. 147)
}

Por isso é que se pode e se deve classificar remuneração como repasse de custos direta ou indiretamente cobrados. No que diz respeito à cobrança indireta, inclusive, destaca- se que ela pode nem estar ligada ao consumidor beneficiário da suposta "gratuidade". Pode-se entender que seu custo está embutido em outro produto adquirido pelo próprio consumidor, 
como por exemplo, o bilhete aéreo comprado ou o combustível para o seu veículo, entre outros.

Hoje se considera que uma série de relações de massa, direta e indiretamente ligadas ao consumo, como a publicidade, os bancos de dados, as amostras e produtos gratuitos ou em forma de prêmios, sorteios, brindes, convites e jogos, o transporte gratuito conexo ao consumo e o transporte gratuito de certas pessoas, os prêmios de milhagem etc., mesmo que gratuitos, são remunerados indiretamente na sociedade de consumo e incluem-se no artigo $3^{\circ}$, parágrafo $2^{\circ}$, do CDC como relações de consumo.

Note-se, porém, que muitas destas relações "gratuitas" podem possuir um regime especial, como oferta especial que são (regras sobre os prêmios, milhagens, jogos etc.), que deve ser seguido, se não abusivo, em face da sua gratuidade. Note-se, igualmente, que, justamente por serem remuneradas indiretamente por terceiros, pela coletividade ou mesmo pelos fornecedores, não deixam de ser reguladas, em seus aspectos básicos, pelas normas e princípios do CDC, especialmente no que se refere à boa-fé, lealdade e cuidado entre fornecedores e consumidores no mercado de consumo. (MARQUES, 2010, p. 653)

A pedra de toque aqui parece ser o interesse negocial de consumo intrínseco nesta relação teoricamente gratuita. Como há interesse negocial, há lucro, há marketing, há prática comercial visando consumo, há fornecimento de serviço, há consumidor destinatário final (artigo $2^{\circ}$, do $\mathrm{CDC}$ ), há consumidor equiparado porque incidentalmente relacionado ou exposto às práticas comerciais, e pode haver consumidor vítima do fato do serviço. Assim, estas ofertas especiais (frutos do marketing de consumo e da vontade de fidelizar e atrair os consumidores) são ofertas de consumo reguladas pelo CDC e seus princípios, devem ser verdadeiras, leais e cumpridas como o prometido.

Estas atividades dos fornecedores visam lucro, são parte de seu marketing e de seu preço total, pois são remunerados indiretamente na manutenção do negócio principal e das concessões da linha, na fidelidade dos consumidores daí oriunda (exemplo: cartões de milhagem etc.), nos efeitos positivos do marketing usado, enfim, no preço final do serviço ou produto colocado no mercado por aquele fornecedor. (MARQUES, 2010, p. 159)

Na prática, só existem três possibilidades:

a) Ou o serviço é remunerado diretamente pelo consumidor;

b) Ou o serviço não é oneroso para o consumidor, mas remunerado indiretamente, não havendo enriquecimento ilícito do fornecedor, pois o seu enriquecimento tem causa no contrato de fornecimento de serviço, causa esta que é justamente a remuneração indireta do fornecedor; 
c) Ou o serviço não é oneroso de maneira nenhuma (serviço gratuito totalmente) e nem o fornecedor remunerado de nenhuma maneira, pois, se este fosse remunerado indiretamente, haveria enriquecimento sem causa de uma das partes.

Vale a menção jurisprudencial a seguir:

Programa de milhagem - Aplicação do Código de Defesa do Consumidor Condições alteradas - Menos vantagens - Possibilidade - Natureza do contrato Previsão no contrato quanto a alterações. Os programas de milhagem oferecidos pelas empresas aéreas estão submetidos às regras do Código de Defesa do Consumidor, entretanto, não pode o consumidor pretender a perpetuação das condições que lhes são mais favoráveis se há cláusula prevendo a possibilidade de sua alteração e, ainda, se considerarmos a própria natureza do programa, como vantagem, ato de liberalidade da companhia aérea. É nula a clausula na parte em que prevê a alteração do contrato sem aviso prévio do consumidor. Recurso não provido. (TAMG - Ap. Cív. 437991-1 - rel. Juiz Pereira da Silva - j. 23.11.2004).

Portanto, no mercado de consumo, em quase todos os casos, há remuneração do fornecedor, direta ou indireta, como um exemplo do "enriquecimento" dos fornecedores pelos serviços ditos "gratuitos" pode comprovar.

\section{CONCLUSÃO}

A partir da aceitação do Código de Defesa do Consumidor como um microssistema de garantias constitucionais aplicáveis às relações entre particulares e fornecedores, chega-se ao entendimento que é possível tutelar as relações sociais no mundo moderno caracterizado pela liquidez das coisas.

O sistema capitalista, o mercado de consumo, a globalização e a substituição do "ser" pelo "ter" na busca da felicidade geram um ambiente insalubre quanto à manutenção dos direitos dos consumidores, surgindo então, a necessidade do Estado através do poder público, insurgir-se às relações sociais privadas.

A ascensão dos direitos metaindividuais, difusos e individuais homogêneos introduz uma nova roupagem ao Direito e, consigo, uma ampla responsabilidade social, de tutelas regional, estadual e universal. E neste contexto os direitos decorrentes da relação de consumo passam a ter maiores garantias constitucionais, maior proteção do poder público e do Estado, bem como um caráter de norma pública.

Verifica-se, quanto, aos programas de milhas que, estes constituem uma nova forma de aquisição de produtos e serviços, tomando forma de "moeda", crédito ou valor monetário, em que pesem as devidas proporções. 
Quanto ao mercado de consumo, em quase todos os casos, há remuneração do fornecedor, direta ou indireta, como um exemplo do "enriquecimento" dos fornecedores pelos serviços ditos "gratuitos" pode comprovar.

Portanto, com esta pesquisa, conclui-se que as milhas aéreas devam ser consideradas produtos e/ou serviços indiretamente remunerados, com natureza jurídica de moeda, constituindo-se, ainda, como crédito transmissível a terceiros, inclusive causa mortis. Como se trata de um instituto moderno, o ordenamento jurídico brasileiro deve se readequar a esses novos contratos e novos direitos. E com isso, observam-se os impactos para o Direito do Consumidor nessas novas relações jurídicas.

\section{REFERÊNCIAS}

AGÊNCIA NACIONAL DE AVIAÇÃO CIVIL - ANAC. Disponível em http://www.anac.gov.br/. Acesso em 10 de julho de 2015.

\begin{tabular}{|c|c|c|c|}
\hline DCIAÇÃO & ANALISTAS & PROFISSIONAIS DE & INVESTIMENTO \\
\hline MERCADO & CAPITAIS & APIMEC. & Disponível \\
\hline
\end{tabular}

BRASIL. Código Brasileiro de Aeronáutica. Disponível em http://presrepublica.jusbrasil.com.br/legislacao/91749/codigo-brasileiro-de-aeronautica-lei$\underline{7565-86}$. Acesso em 10 de julho de 2015.

Código de Defesa do Consumidor. Disponível em http://www.planalto.gov.br/CCIVIL_03/leis/L8078.htm. Acesso em 10 de julho de 2015.

Constituição $\quad$ Federal. $\quad$ Disponível em http://www.planalto.gov.br/ccivil_03/constituicao/constituicaocompilado.htm. Acesso em 10 de julho de 2015.

Projeto de Lei 4015/2012. Disponível em http://www.camara.gov.br/proposicoesWeb/fichadetramitacao?idProposicao=547059 Acesso em 10 de julho de 2015.

DOTZ. Disponível em https://www.dotz.com.br/preHome.aspx. Acesso em 10 de julho de 2015.

IPIRANGA KILOMETROS DE VANTAGEM. Disponível em https://www.kmdevantagens.com.br/wps/portal/kmv. Acesso em 10 de julho 2015.

MARQUES, Claudia Lima. Revista de Direito do Consumidor. Vol. 60. São Paulo: Editora Revista dos Tribunais, 2006. 
Comentários ao Código de Defesa do Consumidor. 3. ed. rev., atual. e ampl. São Paulo: Editora Revista dos Tribunais, 2010.

MULTIPLUS. Disponível em https://www.multiplusfidelidade.com.br/home/. Acesso em 10 de julho de 2015.

NETPOINTS. Disponível em http://www.netpoints.com.br/. Acesso em 10 de julho de 2015.

NUNES, Luis Antonio Rizzatto. Curso de Direito do Consumidor. 6. ed. ver. e atual. São Paulo: Saraiva, 2011.

SILVA, Maria Ozanira da Silva e. Avaliação de Políticas e Programas Sociais: teoria e prática. São Paulo: Veras Editora, 2001.

SMILES. Disponível em http://www.voegol.com.br/pt-br/smilesinstitucional/Paginas/programa_smiles.aspx?m=1. Acesso em 10 de julho de 2015.

TAM FIDELIDADE. Disponível em http://www.tam.com.br/b2c/vgn/v/index.jsp?vgnextoid=9727e7cc87951410VgnVCM100000 9508020aRCRD. Acesso em 10 de julho de 2015.

TRIBUNAL DE JUSTIÇA DE MINAS GERAIS. TJMG. Disponível em http://www.tjmg.jus.br/portal/. Acesso em 03 de agosto de 2015. 